\title{
Follicle sinus complexes (FSCs) in muzzle skin as postmortem diagnostic material of rabid dogs
}

\author{
Nozomi SHIWA ${ }^{1)}$, Chikage NAKAJIMA ${ }^{1)}$, Kazunori KIMITSUKI ${ }^{1)}$, \\ Daria Llenaresas MANALO ${ }^{2)}$, Akira NOGUCHI ${ }^{3)}$, Satoshi INOUE ${ }^{3)}$ and \\ Chun-Ho PARK ${ }^{1) *}$
}
1)Department of Veterinary Pathology, School of Veterinary Medicine, Kitasato University, 23-35-1, Higashi, Towada, Aomori 034-8628, Japan
${ }^{2)}$ Veterinary Research Department, Research Institute for Tropical Medicine, Department of Health, 9002 Research Drive, Filinvest Corporate City, Alabang, Muntinlupa City 1781, Philippines
${ }^{3)}$ Department of Veterinary Science, National Institute of Infectious Diseases, Toyama 1-23-1, Shinjuku-ku, Tokyo 162-8640, Japan

\section{J. Vet. Med. Sci. \\ 80(12): 1818-1821, 2018}

doi: 10.1292/jvms.18-0519

Received: 28 August 2018

Accepted: 8 October 2018

Published online in J-STAGE:

17 October 2018
ABSTRACT. Recently, we reported that follicle-sinus complexes (FSCs) in the muzzle skin are useful for postmortem diagnosis of rabid dogs. Here, we compared the sensitivity and specificity of detecting the viral antigen in the brain and FSCs of 226 suspected rabid dogs, and assessed whether the FSC harbored the virus genome and particles. The viral antigen was detected in 211 of 226 samples with $100 \%$ sensitivity and specificity. Viral RNA and particles were observed in the cytoplasm of Merkel cells (MCs). These results suggest that MCs are targets of virus infection and FSCs are useful material for diagnosing rabies.

KEY WORDS: follicle-sinus complex (FSC), Merkel cell, post-mortem diagnosis, rabid dog

Rabies is an incurable disease that is associated with the highest fatality rate of any zoonotic disease [26]. The rabies virus is transmitted to humans by rabid animal bite, where it causes acute encephalomyelitis after a variable incubation period. Canine rabies is endemic in resource-poor regions, which represents more than $80 \%$ of the world's population, where human rabies imposes an economic burden [10]. In the Philippines, domestic dogs are the primary reservoirs of rabies, and more than $98 \%$ of human rabies-associated deaths are due to dog bites [7].

The most widely used test for rabies diagnosis is the direct fluorescent antibody test (dFAT), which is recommended by both the World Organization for Animal Health (OIE) [18] and World Health Organization (WHO) [26]. The sensitivity of dFAT is 100\% when the brain samples are fresh, and definitive diagnosis can be obtained within few hours. However, the sensitivity reduces and the method becomes unsuitable when the brain samples start to decompose under warm temperatures [17]. This can pose a problem in tropical countries where transportation of specimens to regional diagnostic laboratories often entails delay. In addition, sampling of dog brain is laborious, is associated with high risk of virus exposure, and requires expensive equipment such as fluorescent microscopes. Therefore, alternative specimens for postmortem diagnosis of rabid dogs using low-cost and simple tests with low virus-exposure risk are required in rabies-endemic countries.

In animals (except humans), the tactile hair, known as the follicle-sinus complex (FSC), is a specialized touch organ that is abundant in the muzzle skin. Each tactile hair is equipped with more than 2,000 sensory nerve endings [11]. Therefore, tactile hairs may act as alternative postmortem diagnostic material. Recently, we reported that Merkel cells (MCs) in the FSCs of muzzle skin are targets of virus infection and can act as alternative specimen sources for rabies diagnosis [21]. However, the number of FSC samples used was not sufficient to ensure definite diagnosis and the results did not confirm the presence of the viral genome and particles in the MCs. The present study provides more information on the post-mortem diagnostic utility of FSCs in the muzzle skin of rabid dogs.

Muzzle skin and brain (hippocampus and medulla oblongata) samples were obtained from 226 suspected rabid dogs, which were submitted to the Research Institute for Tropical Medicine (RITM) of Philippines for postmortem diagnosis of rabies. One hundred and fifty-six dogs were found dead, whereas 70 dogs had been subjected to euthanasia. The 226 dogs (111 males, 78 females, and 37 of unknown sex) ranged in age from 1 month to more than 15 years, with 30 dogs of unknown age. Only 10 of the 226 dogs

*Correspondence to: Park, C.-H.: baku@vmas.kitasato-u.ac.jp

(O2018 The Japanese Society of Veterinary Science

This is an open-access article distributed under the terms of the Creative Commons Attribution Non-Commercial No Derivatives (by-nc-nd) License. (CC-BY-NC-ND 4.0: https://creativecommons.org/licenses/by-nc-nd/4.0/) 
had history of rabies vaccination, 76 dogs had no history of rabies vaccination, and information on rabies vaccination status was not available for the remaining 140 dogs. The primary clinical symptoms of canine rabies infection, such as unprovoked aggressiveness, mad biting of inanimate objects, aimless running, and excessive salivation, were observed in 158 of the $226 \mathrm{dogs}$, and no information was available for the remaining dogs. Muzzle skin and brain from five rabiesvaccinated experimental beagle dogs ( 3 males and 2 females, aged 10 months) were used as negative controls.

Small transverse sections ( $2-3 \mathrm{~mm}$ in thickness) of the Ammon's horn and brain stem of the 226 dogs were excised, and a slide was touched against the cut surfaces, after which the slides were placed on cold acetone overnight for fixation. After fixation, the slides were air-dried at room temperature (RT). Next, $450 \mu l$ fluorescence isothiocyanate-conjugated anti-rabies monoclonal antibody (Fujirebio, Malvern, PA, U.S.A.) was added and the slides were incubated for $30 \mathrm{~min}$ at $37^{\circ} \mathrm{C}$ in a high-humidity chamber. The slides were examined under a fluorescence microscope (80i, Nikon, Tokyo, Japan).

Muzzle skin samples of the 226 rabies-suspected dogs were fixed in 10\% neutral-buffered formalin at RT for more than $72 \mathrm{hr}$. Muzzle skins, including FSCs, were cut into transverse sections as recommended in our previous study [21]. The transverse sections were made at the level of the ring sinus of the FSCs identified using stereoscopic microscopy (MZ7.5; Leica, Morrisville, NC, U.S.A.). The samples were embedded in paraffin, sectioned at a thickness of $3 \mu \mathrm{m}$, and mounted. The sections were stained with hematoxylin and eosin (HE) and the serial sections were subjected to immunohistochemistry (IHC) as described below.

For detecting the rabies virus antigen in tissues, sections were stained using the polymer method with rabbit polyclonal rabies antiphosphoprotein antibody (anti-P) as described previously $[4,23]$. To identify cell types that express the virus antigen, double staining of a single tissue section was performed using an immunofluorescent antibody. To evaluate the relationship between antigen-positive cells and MCs, a combination of anti-P antibody and CAM 5.2 staining was performed as described previously [21].

In situ hybridization (ISH) was performed to compare the distribution of viral RNAs and antigens in the FSCs. ISH of formalinfixed paraffin-embedded tissues was performed using the RNAscope ${ }^{\circledR} 2.5$ HD reagent kit-RED (Advanced Cell Diagnostics, ACD, Newark, CA, U.S.A.) [25]. A probe against RNAscope ${ }^{\circledR}$ probe-V-RABV-gp1 (NC 001542.1, region 59-1482) (ACD\#456781) was used. The slides were processed according to the manufacturer's instructions. Finally, the slides were counterstained with hematoxylin, and mounted using EcoMount (Biocare Medical, Pacheco, CA, U.S.A.).

Transmission electron microscopy (TEM) was performed to observe virus particles in the MCs. Muzzle skin tissues embedded in paraffin wax were cut into 1-mm blocks, deparaffinized, and dehydrated in acetone series. The tissue pieces were washed with PBS, post-fixed for $12 \mathrm{hr}$ at RT in 1\% buffered osmium tetroxide, and embedded in epoxy resin. Approximately 70-nm-thick sections were stained with uranyl acetate and lead citrate and examined using a transmission electron microscope (H-7650, Hitachi, Tokyo, Japan).

The Ammon's horn and brain stem specimens of 211 of 226 suspected rabid dogs were positive by both dFAT and IHC. In 23 of the 211 rabid dogs, mild infiltration of lymphocytes and macrophages were observed in the FSCs, and certain epithelial cells in the outer root sheath located at the ring-wulst areas exhibited apoptotic features such as nuclear fragmentation and cytolysis. Negri bodies were not observed in the FSCs of these 211 rabid dogs.

The viral antigen was detected in the brain and FSCs of 211 out of 226 suspected rabid dogs using both dFAT and IHC with $100 \%$ sensitivity and specificity, whereas the remaining 15 dogs were viral antigen negative. The virus antigen-positive cells were concentrated in a part of the outer root sheath at the level of the ring-wulst in the FSCs (Fig. 1). The majority of the viruspositive cells stained positively for the CAM5.2 MC marker. Occasionally, the virus antigen was observed in the peripheral nerves surrounding the FSCs and the perifollicular nerves in the ordinary follicles (Fig. 1). The distribution patterns of CAM5.2 in the muzzle skin of the negative controls were similar to those in rabid dog muzzle skin, although the viral antigen was not detected. The majority of anti-P-positive cells were positive for CAM5.2.

ISH signals were detected in the MC cytoplasm of FSCs, similar to that observed in IHC. The staining intensity of ISH was slightly lower than that of IHC (Fig. 1, insert).

MCs were observed in the basal layer of the outer root sheath at the height of in the FSCs and were surrounded by a thin glassy membrane per TEM observation. The MCs possessed invaginated nuclei, and vacuoles of various sizes, fine filaments, mitochondria, rough endoplasmic reticulum, and free ribosomes were observed in the cytoplasm. The number of mitochondria was 


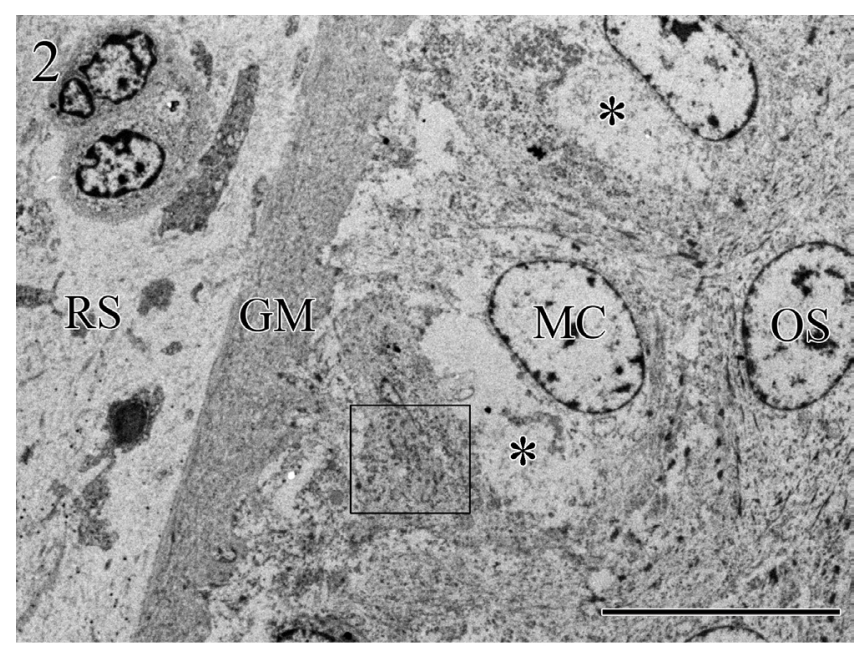

Fig. 2. Transverse sections of the FSC in the muzzle skin of a rabid dog. Merkel nerve endings $(*)$ were observed between the glassy membrane (GM) and squamous cells in the outer root sheath (OS). GM: glassy membrane, MC: Merkel cells, OS: outer root sheath, RS: ring sinus. *: nerve endings. Transmission electron microscopy, bar $=10 \mu \mathrm{m}$.

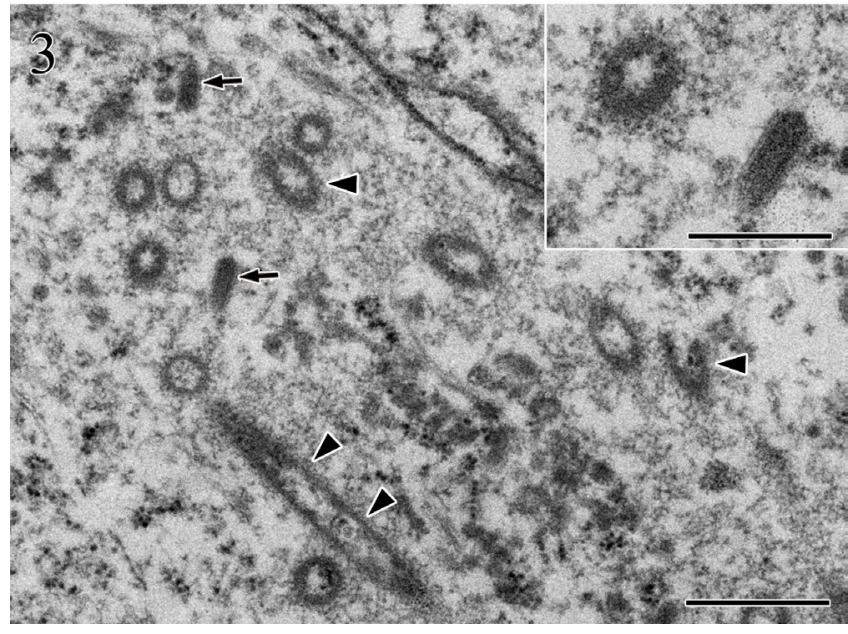

Fig. 3. Higher magnification of boxed area in Fig. 2. Bullet-shaped virus particles (arrows) and virus-associated structures (arrowheads) were observed in the matrix in the cytoplasm of Merkel cells. Transmission electron microscopy, bar $=10 \mu \mathrm{m}$ (insert, bar=200 nm).

high and several membrane-bound dense core granules (neuroendocrine granules) were observed in areas rich in nerve endings (Fig. 2). Virus particles (approximately 150 to $200 \mathrm{~nm}$ in length, $70 \mathrm{~nm}$ wide) were observed in the rough endoplasmic reticulum, nerve endings, and matrix of MCs. Occasionally, virus-associated structures were observed in the cytoplasmic matrix of MCs (Fig. 3). These structures, which were 500 to $1,000 \mathrm{~nm}$ long and 100 to $200 \mathrm{~nm}$ wide, showed high electron density, and elliptical to stringy shapes.

The FSC is a specialized touch organ. All mammals except humans possess FSCs that are concentrated in the muzzle skin. Each FSC contains 500-2,000 MCs and 20-100 lanceolate nerve endings [8, 11, 19]. Merkel endings are composed of MCs and the sensory nerve, which penetrate the glassy membrane of FSCs $[8,19]$. In the present study, viral antigens and genome were detected in the outer root sheath cells at the ring-wulst areas of the FSCs, and these cells stained positively for the MC marker CAM5.2. These results are consistent with those of our previous report [21], which suggested that rabies virus descends via the superior maxillary nerve to the trigeminal nerve and reaches the MC nerve endings in FSCs, where they replicate at late stage of infection.

In the CNS, rabies virus infection induces the formation of cytoplasmic inclusion bodies called Negri bodies [14]. As these structures are typically observed in the pyramidal neurons of the hippocampus and cerebral cortex and Purkinje cells of the cerebellum of rabies-infected animals, they have diagnostic value and have been used for definite histological diagnosis. In contrast to CNS, Negri bodies are not observed in epithelial cells of salivary glands, nasal glands, chromaffin cells of adrenal glands, and skin [1]. In general, inclusions are considered as side-products of the infectious process due to the passive accumulation of large quantities of protein produced during infection. Recently, Lahaye et al. [15] reported that Negri bodies are sites of viral transcription and replication, and contain viral RNA, N and P proteins, heat shock protein Hsp70, Toll-like receptor 3, and ubiquitinylated proteins in in vitro experiments. In the present study, viral P protein, RNA, particles, and virus-associated structures were detected by IHC, ISH, and electron microscopy; however, Negri bodies were not observed in the MCs of FSCs. The reason why inclusion bodies were not formed in MCs is unknown; however, differences in the cytoskeleton of brain nerve cells and MCs may be responsible for this observation. In fact, unlike neurons, MCs do not possess axons. In the present study, virus-associated structures were detected mixed with virus particles in the cytoplasm of MCs. Similar structures were previously reported in rabies virus [12, 16, 20] and pox virus in monkeys [6]. However, the morphogenesis and importance of these structures in virus infection are still unknown and warrant further investigations.

Skin biopsies are useful for ante- and postmortem diagnosis of humans [3] and animals [2, 22]. Blenden et al. reported that the rabies viral antigen was detected in the hair follicle not only at the onset of clinical symptoms, but also in the early stages (4 days before manifesting clinical signs) in experimental mice infected with street rabies virus [2]. In contrast, the virus antigen was not detected in the muzzle skin of dogs infected with the street rabies virus prior to the appearance of rabies symptoms [9]. In humans, viral antigens are mainly detected in the peripheral nerves surrounding the hair follicles [24], and their number increases with progress in the clinical course of the infection [3]. In the present study, virus antigen-positive reaction was observed in the FSCs in dead or euthanized dogs. Therefore, it was assumed that FSCs of rabid dogs are suitable as postmortem diagnostic materials.

Previously, immunofluorescence-based routine laboratory tests for intravitam diagnosis of rabies in human skin biopsy specimens had indicated that a minimum of 20 sections was required to observe the hair follicles [5]. In addition, the skin biopsy sample should contain at least 10 hair follicles [13]. In the present study, the number of FSCs required for a reliable 
histopathological diagnosis was not evaluated; therefore, further investigations are required to refine the use of FSCs as a novel diagnostic material for canine rabies.

In summary, our study showed that the rabies virus antigen can be detected with high sensitivity and specificity, and viral mRNA and particles were observed in the MCs of the muzzle skin FSCs, indicating that MCs are the target for rabies virus infection and replication. Thus, FSCs are useful as alternative tissue sources for postmortem diagnosis of rabies. In addition, sampling FSCs is easier and safer than sampling brain tissue. Thus, FSCs might be used in epidemiological studies of both domestic and wild animal rabies, especially in rabies-endemic areas of developing countries.

ACKNOWLEDGMENTS. The authors acknowledge the invaluable assistance of the staff at the Research Institute for Tropical Medicine (RITM), Department of Health, Philippines, for tissue collection from dogs and the permission to use these samples in the current study. This work was supported by a Grant-in-Aid for Scientific Research from the Japan Society for the Promotion of Science (Kakenhi No. 26450410), the Grant for Scientific Research from the Kitasato University, Heiwa Nakajima Foundation, Japan Agency for Medical Research and Development (AMED), and AMED/JICA, SATREPS, Japan

\section{REFERENCES}

1. Balachandran, A. and Charlton, K. 1994. Experimental rabies infection of non-nervous tissues in skunks (Mephitis mephitis) and foxes (Vulpes vulpes). Vet. Pathol. 31: 93-102. [Medline] [CrossRef]

2. Blenden, D. C., Bell, J. F., Tsao, A. T. and Umoh, J. U. 1983. Immunofluorescent examination of the skin of rabies-infected animals as a means of early detection of rabies virus antigen. J. Clin. Microbiol. 18: 631-636. [Medline]

3. Blenden, D. C., Creech, W. and Torres-Anjel, M. J. 1986. Use of immunofluorescence examination to detect rabies virus antigen in the skin of humans with clinical encephalitis. J. Infect. Dis. 154: 698-701. [Medline] [CrossRef]

4. Boonsriroj, H., Manalo, D. L., Kimitsuki, K., Shimatsu, T., Shiwa, N., Shinozaki, H., Takahashi, Y., Tanaka, N., Inoue, S. and Park, C. H. 2016. A pathological study of the salivary glands of rabid dogs in the Philippines. J. Vet. Med. Sci. 78: 35-42. [Medline] [CrossRef]

5. Crepin, P., Audry, L., Rotivel, Y., Gacoin, A., Caroff, C. and Bourhy, H. 1998. Intravitam diagnosis of human rabies by PCR using saliva and cerebrospinal fluid. J. Clin. Microbiol. 36: 1117-1121. [Medline]

6. De Harven, E. and Yohn, D. S. 1966. The fine structure of the Yaba monkey tumor poxvirus. Cancer Res. 26: 995-1008. [Medline]

7. Dimaano, E. M., Scholand, S. J., Alera, M. T. and Belandres, D. B. 2011. Clinical and epidemiological features of human rabies cases in the Philippines: a review from 1987 to 2006. Int. J. Infect. Dis. 15: e495-e499. [Medline] [CrossRef]

8. Ebara, S., Kumamoto, K., Matsuura, T., Mazurkiewicz, J. E. and Rice, F. L. 2002. Similarities and differences in the innervation of mystacial vibrissal follicle-sinus complexes in the rat and cat: a confocal microscopic study. J. Comp. Neurol. 449: 103-119. [Medline] [CrossRef]

9. Fekadu, M. and Shaddock, J. H. 1984. Peripheral distribution of virus in dogs inoculated with two strains of rabies virus. Am. J. Vet. Res. 45: 724-729. [Medline]

10. Fooks, A. R., Banyard, A. C., Horton, D. L., Johnson, N., McElhinney, L. M. and Jackson, A. C. 2014. Current status of rabies and prospects for elimination. Lancet 384: 1389-1399. [Medline] [CrossRef]

11. Halata, Z. 1993. Sensory innervation of the hairy skin (light- and electronmicroscopic study. J. Invest. Dermatol. 101 Suppl: 75S-81S. [Medline] [CrossRef]

12. Iseni, F., Barge, A., Baudin, F., Blondel, D. and Ruigrok, R. W. 1998. Characterization of rabies virus nucleocapsids and recombinant nucleocapsidlike structures. J. Gen. Virol. 79: 2909-2919. [Medline] [CrossRef]

13. Jackson, A. C. 2011. Update on rabies. Res. Rep. Trop. Med. 2011: 31-43. [CrossRef]

14. Kristensson, K., Dastur, D. K., Manghani, D. K., Tsiang, H. and Bentivoglio, M. 1996. Rabies: interactions between neurons and viruses. A review of the history of Negri inclusion bodies. Neuropathol. Appl. Neurobiol. 22: 179-187. [Medline] [CrossRef]

15. Lahaye, X., Vidy, A., Pomier, C., Obiang, L., Harper, F., Gaudin, Y. and Blondel, D. 2009. Functional characterization of Negri bodies (NBs) in rabies virus-infected cells: Evidence that NBs are sites of viral transcription and replication. J. Virol. 83: 7948-7958. [Medline] [CrossRef]

16. Matsumoto, S. 1962. Electron microscopy of nerve cells infected with street rabies virus. Virology 17: 198-202. [Medline] [CrossRef]

17. McElhinney, L. M., Marston, D. A., Brookes, S. M. and Fooks, A. R. 2014. Effects of carcase decomposition on rabies virus infectivity and detection. J. Virol. Methods 207: 110-113. [Medline] [CrossRef]

18. OIE 2017. Rabies. Chapter 2. 1. 17. pp. 1-28. In: Manual of Diagnostic Tests and Vaccines for Terrestrial Animals 2017, World Organization for Animal Health.

19. Sarko, D. K., Reep, R. L., Mazurkiewicz, J. E. and Rice, F. L. 2007. Adaptations in the structure and innervation of follicle-sinus complexes to an aquatic environment as seen in the Florida manatee (Trichechus manatus latirostris). J. Comp. Neurol. 504: 217-237. [Medline] [CrossRef]

20. Sheikh, K. A., Ramos-Alvarez, M., Jackson, A. C., Li, C. Y., Asbury, A. K. and Griffin, J. W. 2005. Overlap of pathology in paralytic rabies and axonal Guillain-Barre syndrome. Ann. Neurol. 57: 768-772. [Medline] [CrossRef]

21. Shimatsu, T., Shinozaki, H., Kimitsuki, K., Shiwa, N., Manalo, D. L., Perez, R. C., Dilig, J. E., Yamada, K., Boonsriroj, H., Inoue, S. and Park, C. H. 2016. Localization of the rabies virus antigen in Merkel cells in the follicle-sinus complexes of muzzle skins of rabid dogs. J. Virol. Methods 237: 40-46. [Medline] [CrossRef]

22. Smith, W. B., Blenden, D. C., Fuh, T. H. and Hiler, L. 1972. Diagnosis of rabies by immunofluorescent staining of frozen sections of skin. J. Am. Vet. Med. Assoc. 161: 1495-1501. [Medline]

23. Shoji, Y., Inoue, S., Nakamichi, K., Kurane, I., Sakai, T. and Morimoto, K. 2004. Generation and characterization of P gene-deficient rabies virus. Virology 318: 295-305. [Medline] [CrossRef]

24. Tobiume, M., Sato, Y., Katano, H., Nakajima, N., Tanaka, K., Noguchi, A., Inoue, S., Hasegawa, H., Iwasa, Y., Tanaka, J., Hayashi, H., Yoshida, S., Kurane, I. and Sata, T. 2009. Rabies virus dissemination in neural tissues of autopsy cases due to rabies imported into Japan from the Philippines: immunohistochemistry. Pathol. Int. 59: 555-566. [Medline] [CrossRef]

25. Wang, F., Flanagan, J., Su, N., Wang, L. C., Bui, S., Nielson, A., Wu, X., Vo, H. T., Ma, X. J. and Luo, Y. 2012. RNAscope: a novel in situ RNA analysis platform for formalin-fixed, paraffin-embedded tissues. J. Mol. Diagn. 14: 22-29. [Medline] [CrossRef]

26. World Health Organization 2013. WHO expert consultation on rabies. Second report. World Health Organ. Tech. Rep. Ser. 982: 1-139. [Medline] 